\title{
LA BÓVEDA TABICADA: ENTRE LA CONSERVACIÓN Y LA DESTRUCCIÓN
}

\section{(THE TILE VAULT: CONSERVATION OR DESTRUCTION)}

\section{José Luis González Moreno-Navarro}

Dr. Arquitecto. Catedrático de Construcción Arquitectónica en la Escuela Técnica Superior de Arquitectura de Barcelona. Universidad Politécnica de Cataluña

Fecha de recepción: 2-III-05

ESPAÑA

\section{RESUMEN}

El singular elemento constructivo histórico denominado bóveda tabicada se encuentra en un momento de su historia delicado. Según sea el curso de los acontecimientos, puede ocurrir que, por desconocimiento e incomprensión de una buena parte de los profesionales de la restauración o rehabilitación, desaparezcan para siempre muchos de los ejemplares que nuestra particular historia de la construcción nos ha legado. Pero, también puede ocurrir lo contrario, es decir, que una nueva sensibilidad por la materialidad del patrimonio lleve a promover la definitiva conservación de todos los abundantes casos que, afortunadamente, todavía se mantienen en pie.

Este artículo aporta ejemplos con los se comprueba que cualquiera de las dos tendencias podría ser la dominante en un futuro próximo. Su autor es partidario, obviamente, de que lo sea la segunda y por ello lo escribe.

\section{SUMMARY}

This is a crucial moment for the historically singular construction element known as the tile vault. A lack of knowledge or understanding on the part of a substantial number of the professionals engaging in restoration and rehabilitation may occasion the disappearance, forevermore, of many of the structures that form a part of the history of Spanish construction. But the opposite may also occur, i.e., a new sensibility towards our material heritage may lead to the permanent conservation of the many such vaults that are fortunately still standing.

According to the evidence discussed in this article and depending on the course of events, either of the two trends may prevail in the near future. The author's obvious preference for the latter served as inspiration for this article.

\section{DESTRUCCIÓN: DOS CASOS DE HACE ALGUNOS AÑOS}

En la página 38 de la más reciente aportación al conocimiento de la bóveda tabicada ${ }^{(1)}$ aparece la figura reproducida aquí con el número 1 que se describe allí con el siguiente detalle: Se trata de la Iglesia Parroquial de San Francisco de Paula (Barcelona 1950. Arquitecto D. E. Pedro Cendoya). La cubierta propiamente dicha está constituida por una bóveda cilindrica atirantada ACE de dos gruesos de rasilla y uno de ladrillo (...) con una directriz con la forma del antifunicular de cargas. La descripción se completa con el sistema de atirantado y la realización del faldón.

En la página 48 del ejemplar de El País del 28 de octubre de 1999, ilustrando un artículo que lleva por título

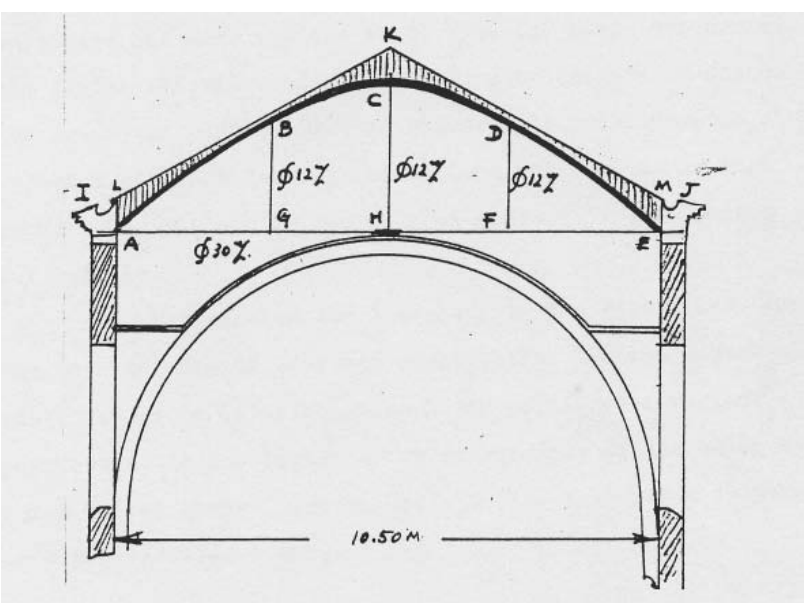

Figura 1.- Dibujo de Ángel Truñó representando la bóveda de la Figura 2 . 


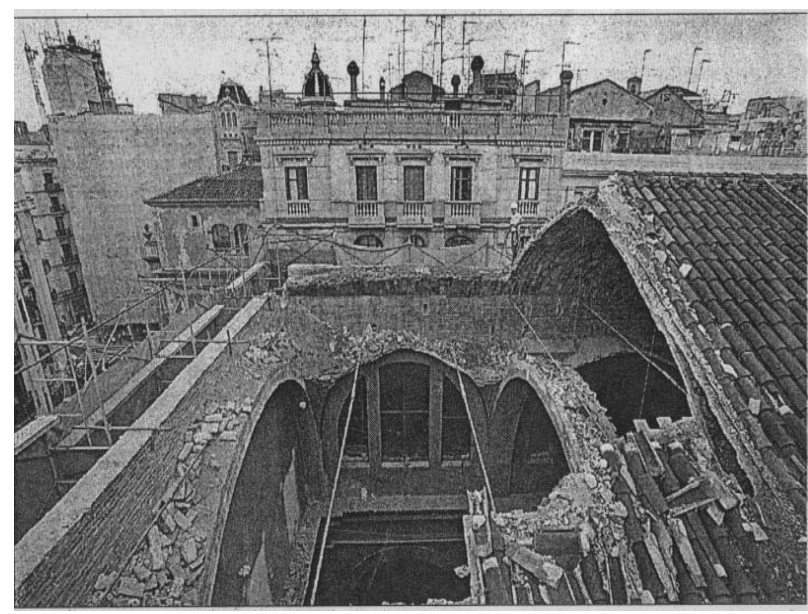

Figura 2.- Bóveda representada en la figura len proceso de destrucción.

\section{"Tusquets revela la cara oculta del Palau de la Música} en su proyecto de ampliación", aparece la foto que se reproduce en la Figura 2, que tiene por pie: "aspecto del derribo de la iglesia colindante al Palau de la Música de Barcelona".

Como se puede deducir, las dos Figuras, 1 y 2 , hacen referencia al mismo edificio.

Para el periodista de 1999 la citada parroquia no tiene entidad en sí misma sino que es sólo "colindante". Si buscamos alguna otra referencia en la prensa barcelonesa de esos días, no vamos a encontrar nada más que explicaciones alrededor tanto de la mediática ampliación del Palau de la Música Catalana como de su mediático autor. La destrucción de una iglesia "colindante" y un magnífico ejemplar de la bóveda tabicada catalana no supusieron el más mínimo hecho noticioso.

Ha de quedar claro que no estoy defendiendo que el Palau no de debería haberse ampliado o la iglesia no se debería haber derribado; no entro en esa discusión. Lo que duele es que esa destrucción de un singular elemento de nuestra identidad constructiva histórica, tanto de Cataluña como de una buen parte de España, ocurriera con la más absoluta indiferencia del colectivo de arquitectos (con su sede bien cercana al lugar). Hubiera sido, cuando menos, una buena ocasión para incrementar el conocimiento que tenemos de ese elemento.

Por desgracia, éste no es sino uno más de los muchos casos en los que han desaparecido bóvedas a la catalana con el total desconocimiento por parte de los que las han destruido.

En ese mismo año se difundió otro caso, esta vez a través del medio televisivo. No tengo más referencia que mi memoria, aunque es suficientemente vivo el recuerdo. Con ocasión de los trabajos de reconstrucción del incendiado teatro del Liceu de Barcelona, uno de los arquitectos que estaba interviniendo en ellos, en una entrevista emitida por TV3, afirmó algo así como que "bajo el pavimento de la Sala de los Espejos se encontró una bóveda muy delgada que no aguantaba nada y que hubo que reforzarla con hormigón armado". Desde hace ciento y pico años, la sala, a la que no afectó el incendio, en los entreactos se ha llenado por completo de espectadores y esa bóveda "tan delgada", construida en Barcelona y en la segunda mitad del siglo XIX no podía ser otra cosa que una tabicada. Un caso más de desnaturalización por desconocimiento.

\section{UN CASO RECIENTE}

Si repasamos la hemeroteca más reciente, podemos encontrar otro caso con una etiología similar. El día 20 de abril de 2004 todos los periódicos de Barcelona se hicieron eco del drama humano acaecido en uno de los pabellones del hospital de San Pablo, como consecuencia del derrumbamiento imprevisto de una de las cúpulas tabicadas del Hospital de San Pablo. En la Figura 3 aparece la portada de la edición en catalán de El Periódico.

Dado que el suceso está en la vía judicial no es posible dar conclusiones finales, pero si que podemos hacer referencia a una última nota que ha aparecido en la prensa diaria el pasado 10 de febrero: "Indicios de negligencia en el derrumbe de la cúpula del hospital de Sant Pau" (La Vanguardia, pág. 6 de la sección VIVIR).

Es razonable la hipótesis de que lo ocurrido era perfectamente previsible si la cúpula se hubiera estudiado en profundidad. Los graves defectos esenciales de la manera de construir de Doménech i Muntaner las bóvedas en contacto con el exterior en todo el hospital son perfectamente conocidos desde hace muchos años. No se sabe bien por qué Doménech, a pesar de ser un defensor de la bóveda tabicada frente a otros procedimientos ya existentes en la época como el hormigón armado ${ }^{(2)}$, no se fió totalmente

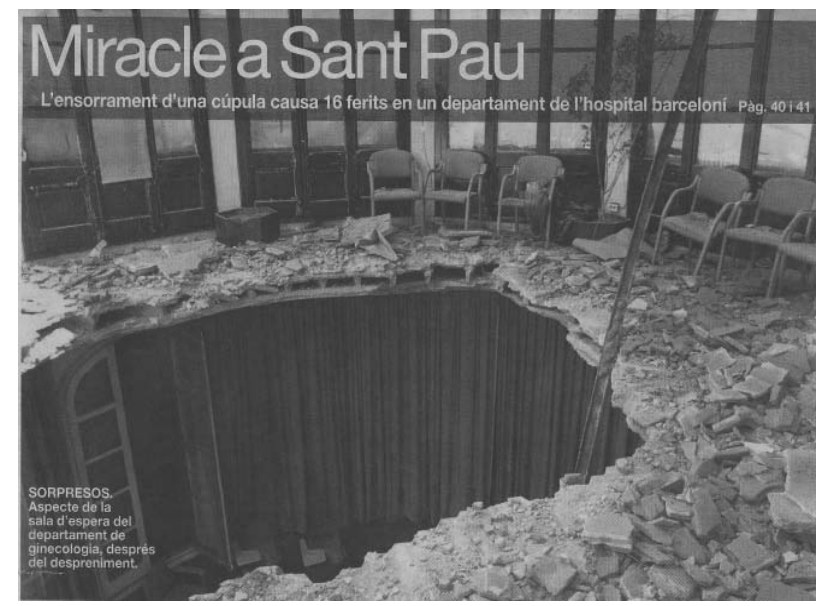

Figura 3.- El título es bien expresivo: Milagro en Sant Pau. La cúpula (que no se ve en la fotografia) cayó sobre la bóveda (cuya "sección" quedó bien visible), suelo de la sala de espera y techo del sótano. 
de su capacidad portante por lo que las reforzó con perfiles metálicos que, al cabo de cien años, bajo una cubierta de escamas de cerámica, prácticamente, han desaparecido. Es bueno recordar que por aquellos mismos años 19051908, Rafael Guastavino construyó entre otras muchísimas, una cúpula sobre el crucero de la catedral de St. John the Divine en Nueva York -unas 5 veces más grande- que se conserva con toda su solidez al no tener en su interior ningún elemento metálico ${ }^{(3)}$.

Las tres referencias anteriores pueden ser suficientes para alimentar la sospecha de que la bóveda tabicada seguirá siendo una perfecta desconocida, por un lado, para arquitectos insensibles a nuestra historia, y, por otro, para los técnicos, que a pesar de ser su obligación desconocen tanto el elemento como su pasado. Su desaparición será su futuro.

\section{CONSERVACIÓN: DOS CASOS RECIENTES}

Sin embargo, también existen indicios de que la situación está en un cierto proceso de cambio. Dos casos pueden ser representativos, dos restauraciones importantes hechas recientemente en Barcelona en las que son protagonistas destacadas las bóvedas tabicadas. La primera es uno de los edificios más extraordinarios de Doménech i Muntaner, la Casa Fuster, en toda su altura construida con bóvedas tabicadas (Fig. 4). La segunda una de las más interesantes obras de la industria textil de final del siglo XIX en la Barcelona industrial del Poble Nou (Fig. 5).

La Casa Fuster ha sido definitivamente convertida, después de varias aventuras no demasiado favorables al edificio y que estuvieron a punto de llevarla a la piqueta, en un hotel de extraordinaria categoría ${ }^{(4)}$. Y la pregunta que era razonable plantearse en el inicio de esa reconversión era qué iba a pasar, a la vista de los casos precedentes, con sus bóvedas tabicadas.

Pues bien, gracias a la intervención de los arquitectos Agustí Obiol y Robert Brufau el edificio se ha conservado en su totalidad las bóvedas tabicadas, manteniendo el esquema mecánico-estructural tal como lo dejó Doménech i Muntaner en su día. Obviamente, han sido necesarios refuerzos parciales y substituciones especialmente en la cubierta del edificio, no tanto por el fallo de las bóvedas tabicadas sino por los elementos metálicos, que, al igual que en el hospital de San Pablo, Doménech parecía no poder resistirse a utilizarlos. Pero el conjunto de las bóvedas de todo el edificio han quedado tal y como las dejó Doménech. El razonamiento expuesto por los responsables para justificar la no necesidad de una intervención a la manera de como se hizo en la desgraciada Casa de la Caridad $^{(5)}$, se basa en una constatación empírica. En 1960 el edificio se reconvirtió en edifico de oficinas, uso que ha tenido durante los últimos 40 años. El nuevo uso de hotel es más liviano, menos agresivo que el administrativo de

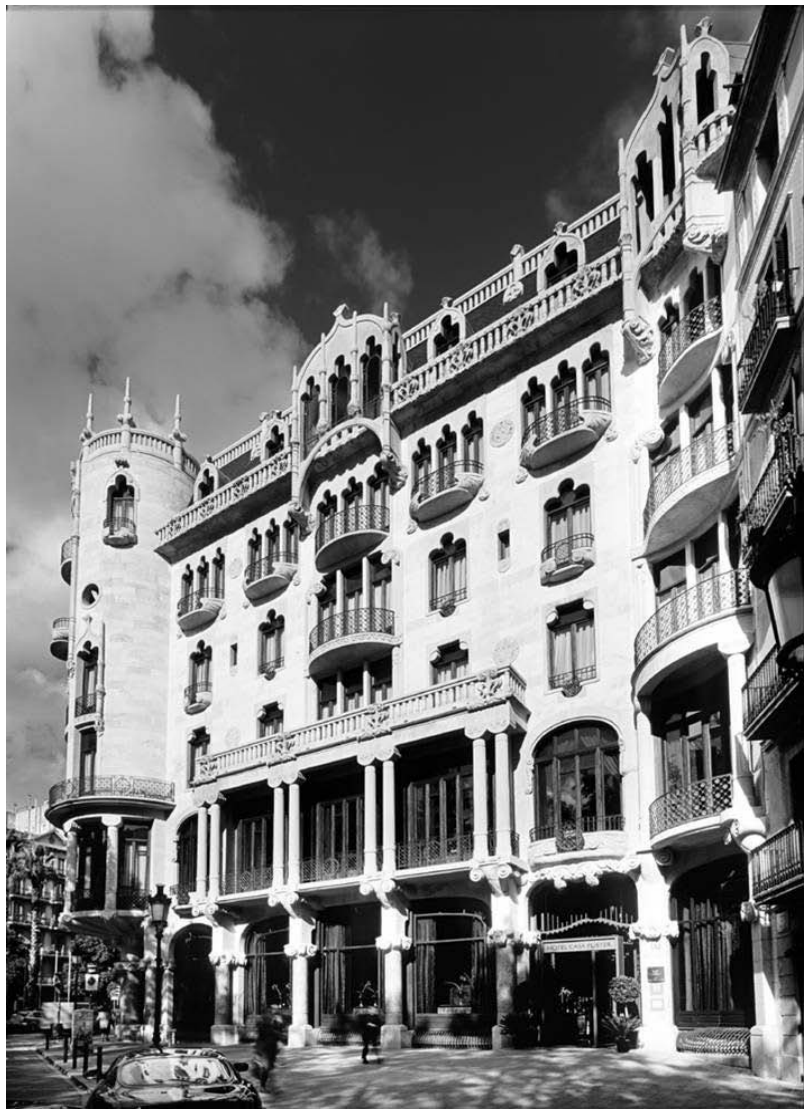

Figura 4.- La Casa Fuster de Domènch i Montaner.

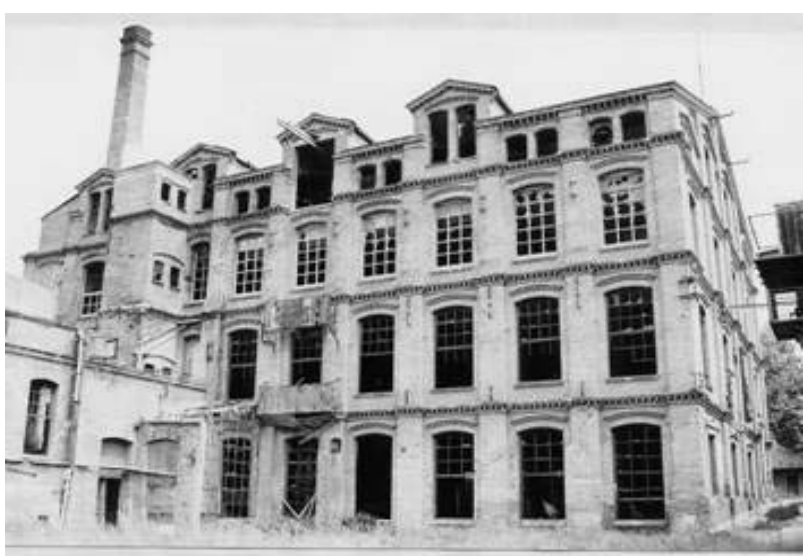

Figura 5.- Edificio alto de la fábrica denominada Ca l'Aranyó.

oficinas. Según eso, la experiencia de los 40 años ha sido suficiente como para poder afirmar que si el uso es más ligero que el anterior, el edificio puede mantenerse en la situación original que estaba sin introducir ningún refuerzo estructural. De hecho no ha sido más que una "prueba de carga" de un realismo total con un nivel de carga superior a la exigible en el nuevo uso.

\section{OTRA PRUEBA DE CARGA}

El otro caso es la transformación del edificio de la industria textil de Ca L'Aranyó en una de las sedes de la Uni- 
versidad Pompeu Fabra ${ }^{(6)}$. Pero antes de entrar en el detalle de la operación es necesario hacer referencia al evento en el que se han presentado estos casos y otros más a los que después haré referencia: el Cursillo de Intervención en el Patrimonio, que ya desde hace 27 años organiza el Colegio de Arquitectos alrededor del día de Santa Lucía ${ }^{(7)}$.

En esta ocasión el tema prioritario ha sido el conocimiento de los aspectos estructurales de la intervención en el patrimonio, y como parecía obligado desde Barcelona se ha dado un protagonismo especial a la bóveda tabicada o catalana

Volvamos al segundo caso, Ca l'Aranyó. Como prácticamente la totalidad de los edificios de este tipo, tanto los diferentes pisos tanto de la nave de 2 plantas como la de 45 plantas, están resueltos mediante bóveda tabicada, y en este caso de manera poco usual, apoyadas en jácenas de fundición a su vez apoyadas en los habituales pilares e fundición. Aplicando un razonamiento similar al de la Casa Fuster, si ha soportado el uso industrial no han sido necesarias más intervenciones constructivas que las derivadas de las inevitables degradaciones debidas al paso del tiempo.

Pero, a la vista de que una de las bóvedas debía derribarse como consecuencia de la adaptación al nuevo uso y de la oportunidad del citado Cursillo, se propuso al promotor la realización de una prueba de carga como continuación de la serie iniciada hace años por el que suscribe estas líneas ${ }^{(8)}$

Para una bóveda de luz de 4 metros de 3 gruesos de rasilla se llegó hasta una carga de $1.900 \mathrm{~kg} / \mathrm{m}^{2}$ sin que se hayan detectado comportamientos locales anómalos, aparición de nuevas fisuras ni movimientos de las fisuras observadas. La flecha máxima bóveda ha sido de $10 \mathrm{~mm}$ y la de la jácena $4,3 \mathrm{~mm}$. Las deformaciones remanentes han sido inferiores al $20 \%$ de los valores anteriores ${ }^{(9)}$ (Fig. 6)

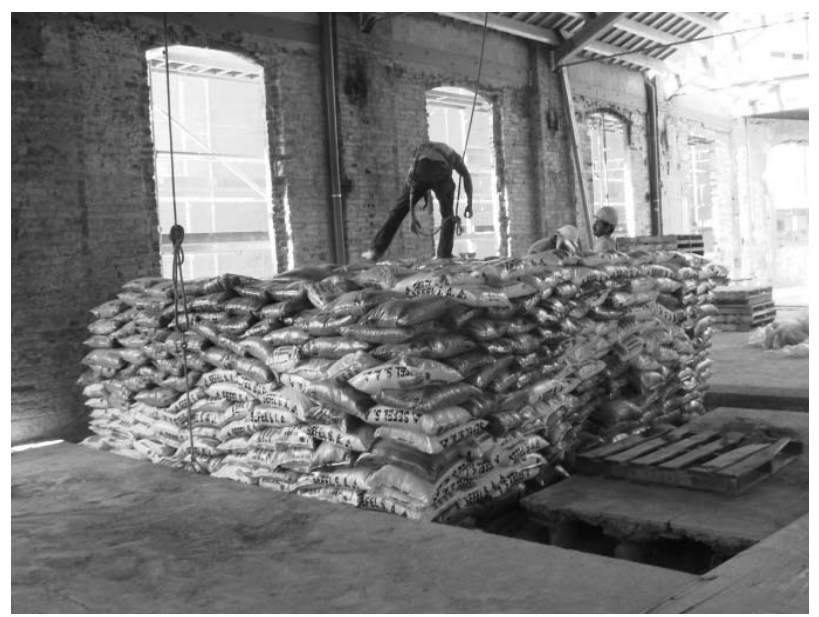

Figura 6.- Último escalón de la prueba de carga realizada sobre una bóveda de Ca l'Aranyó.
Una vez más se comprueba lo ya certificado no sólo por las pruebas citadas sino por la que en su día no tuvo más remedio que realizar Guastavino ${ }^{(10)}$ en los Estados Unidos: la bóveda tiene una extraordinaria capacidad portante ampliamente suficiente para la totalidad de los usos normales incluidos los públicos.

Quede aquí constancia del reconocimiento a la Universidad Pompeu Fabra por haber financiado esta aportación al conocimiento científico de este elemento tan característico de su propia área cultural.

\section{MÁS SOBRE LA CONSERVACIÓN}

A la presentación de los dos casos anteriores les habían precedido tres conferencias sobre la bóveda tabicada ${ }^{(11)}$. Ricardo Gulli nos presentó las interesantísimas experiencias italianas tanto sobre modelos reales de bóvedas como sobre los métodos de refuerzo o restauración. Sobre la aportación de Santiago Huerta creo conveniente dedicarle unas líneas más abajo. Xavier Fabré expuso el proceso que llevó a restaurar y rehabilitar la última obra en España de Rafael Guastavino que fue el principal protagonista de las tres conferencias que cerraron el ciclo dedicado a la bóveda catalana en el Cursillo y que abordaron diferentes aspectos de la extraordinaria obra de los Guastavino en Nueva York ${ }^{(12)}$. Con la magnífica presentación de su tesis doctoral, Mar Loren mostró al público asistente algo que habitualmente los que trabajamos específicamente en el ámbito de la construcción se nos olvida, como es la trascendencia social, cultural y política de la aportación de los Guastavino en Nueva York en la primera mitad del siglo XX (Fig. 7).

Fueron seguidas por la experiencias de dos de los restauradores de los edificios que se conservan actualmente, Kent Diebolt y Charles DiSanto, que gracias a ellos mantendrán durante mucho más tiempo su perfecto estado de conservación. Según ellos, los Guastavinos hicieron sus obras utilizando materiales de gran calidad sin

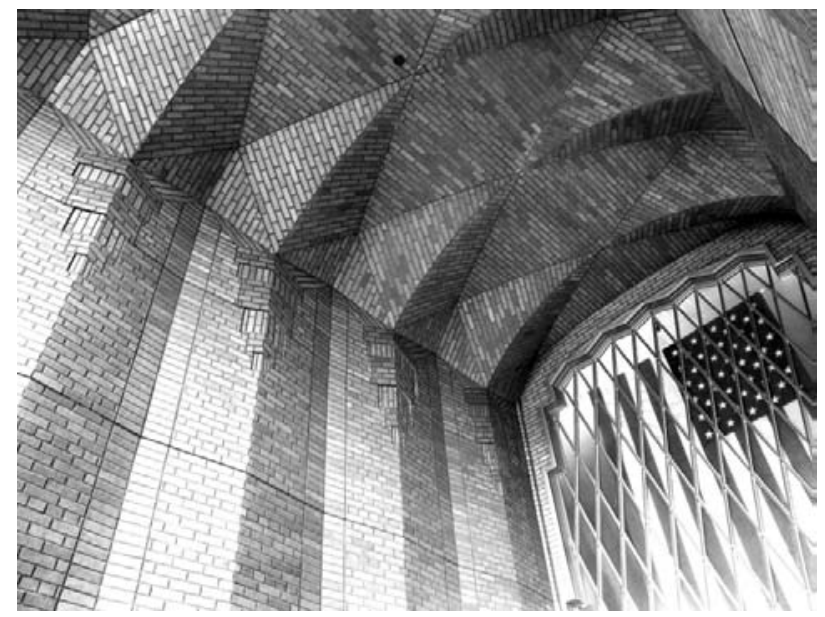

Figura 7.- Vestíbulo del Western Union Building de Nueva York. 
añadir elementos que puedan mermar su durabilidad. Y esto nos lleva a la última parte de este artículo: cuáles son las claves que pueden permitir la conservación del patrimonio de bóvedas que todavía quedan en nuestro país.

\section{LA CAPACIDAD PORTANTE}

A la vista de todo lo expuesto el factor decisivo es su conocimiento, por un lado, como elemento constructivo, sus formas sus materiales, sus aparejos, sus entregas, etc., $y$, por otro, como elemento que ha de aportar un determinada capacidad portante. Sobre esta segunda cuestión creo conveniente matizar las afirmaciones que hizo Santiago Huerta en el Cursillo en su espléndida conferencia, y ha hecho en otras ocasiones ${ }^{(13)}$, que pueden ir en contra, precisamente, y muy a su pesar, de la correcta evaluación de esas capacidades portantes

El método del análisis límite permite entender por qué un conjunto abovedado se mantiene en equilibrio y, sin duda, a la aportación de Jacques Heyman le debemos una enorme parte de nuestra capacidad de comprensión de los edificios históricos. Sin embargo, es un método que no permite determinar, ni aproximadamente, la capacidad portante de una bóveda tabicada por dos razones. En primer lugar, porque dada su delgadez relativa, si bien el trazado puede incluir en su interior y de manera siempre ajustada una línea de presiones, nada podemos saber sobre las inestabilidades de segundo grado. El perfil rebajado de la bóveda de Ca l'Aranyo admite sin duda una línea de presiones, pero una vez encajada ésta es imposible averiguar que soporta hasta aquellos $1.900 \mathrm{~kg} / \mathrm{m}^{2}$ sin ninguna dificultad. Y en segundo lugar, el análisis límite no explica los casos en los que es imposible encontrar ninguna línea de presiones dentro de la masa construida y, sin embargo, existe equilibrio. Dos casos puedo aportar en este sentido. Uno, que ya expuse hace años sobre el paradójico equilibrio de la iglesia de la Colonia Güell de Gaudí (14) y otro, las bóvedas tabicadas de Can Arús, cuya alta capacidad portante, comprobada con una prueba de carga se basa en la colaboración de las lengüetas cuyo efecto no puede modelizar el análisis límite ${ }^{(15)}$. A la vista de todo lo expuesto, se puede defender que el único método es de la prueba de carga específico como el ca l'Aranyó o empírico como el de Casa Fuster. Obviamente, esta cuestión requiere mayor extensión de la nos queda pero al menos sirva lo dicho para incentivar un debate que creo necesario. La deserción del Código Técnico en la batalla de abordar el estudio de los edificios existentes lo hace imprescindible.

\section{EL CONOCIMIENTO CONSTRUCTIVO}

Y ya para acabar, volvamos a la otra de las claves de la conservación de la bóveda tabicada: su conocimiento como elemento constructivo. Y nada mejor que volver al libro con el que hemos iniciado el artículo que también fue ob-

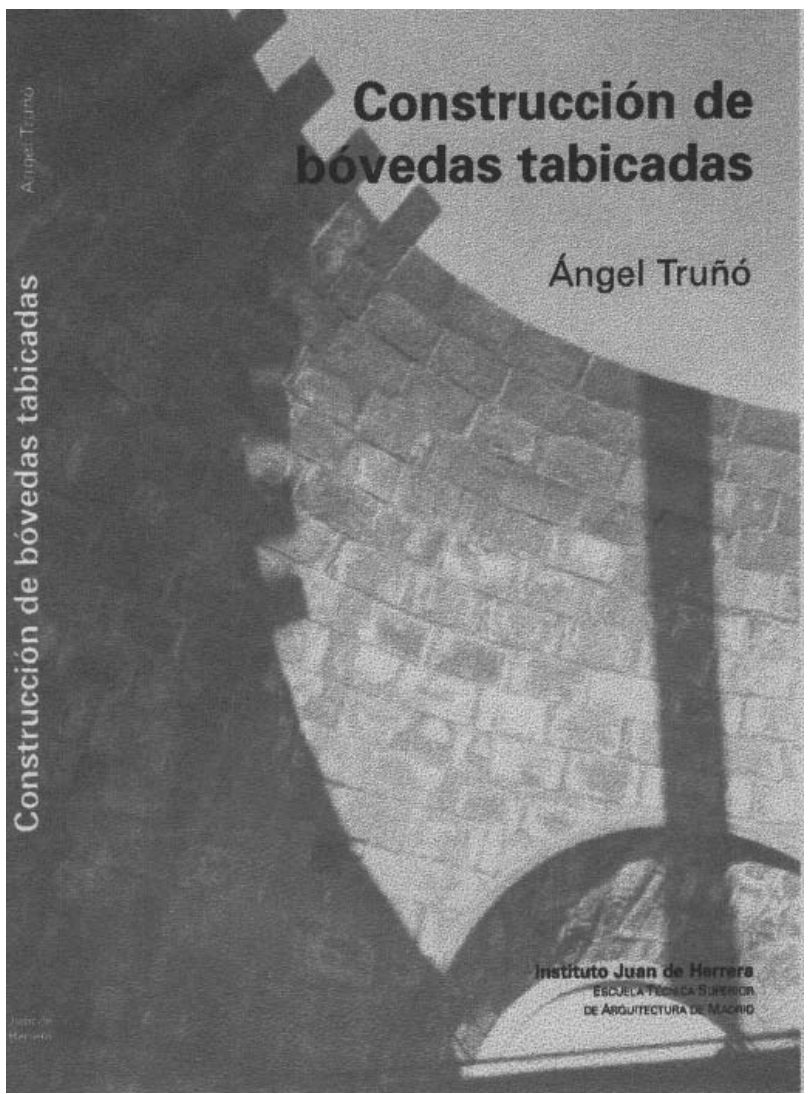

Figura 8.- Portada de la edición actual del mecanoscrito de Ángel Truño

jeto de presentación en el Cursillo del Colegio de Arquitectos (Fig. 8). Su autor, Ángel Truñó (1895-1979) fue un arquitecto y profesor de la Escuela de Arquitectura que, dadas las dificultades de los años de posguerra, no tuvo más remedio que recuperar la técnica de la bóveda tabicada y que, gracias a su sentimiento pedagógico, consiguió verter su extraordinaria experiencia constructiva en este singular libro. Singular por lo que de único tiene, ya que supera, en mucho, en detalle, al que fue escrito por Luis Moya (16). Y es de mucha más difícil lectura, precisamente por ese extraordinario detalle con el que llega a definir las múltiples claves de la bóveda, los múltiples y diferentes aparejos con los que se pueden resolver o las precauciones a tomar durante el proceso, como, por ejemplo, que las cimbras -siempre ligeras- nunca se apoyen sobre el andamio, las precauciones sobre los morteros, el yeso, etc... Y todo eso acompañado de un extraordinario detalle sobre una experiencia concreta como fue la construcción del edifico de San Miguel de los Santos, con bóvedas en rincón de horno, semiesféricas, de cañón con lunetos, óculos de tambor de extraordinaria factura, todo ello explicado con un detalle inusitado en la historia de los libros de construcción (Fig. 9). Es, sin duda, la mejor aportación que se ha podido hacer en los últimos tiempos al conocimiento profundo de este extraordinario elemento.

El final no puede ser, sin embargo, demasiado optimista. No creo que sean muchos los técnicos, arquitectos o de 


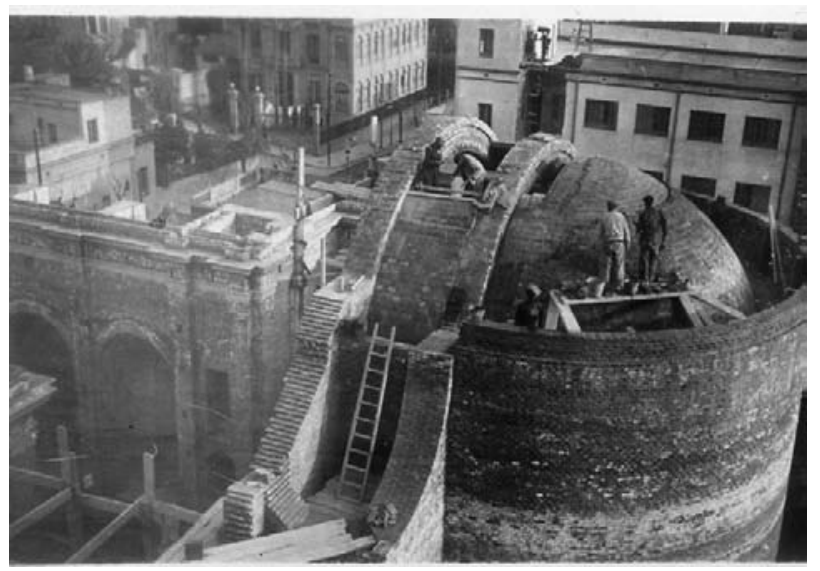

Figura 9.- La iglesia de San Miguel de los Santos de Barcelona en proceso de construcción.

otro perfil, que lo vayan a leer para informarse sobre la bóveda tabicada. En general, los arquitectos surgidos de la Escuela de Arquitectura de Barcelona en los últimos treinta y cinco años, salvo los que han tenido interés por sí mismos, desconocen la existencia en nuestra historia de este elemento tan singular. Me lo hacen ver mis alumnos de últimos años de carrera que cursan mi asignatura optativa sobre edificios históricos cuando se lamentan de que nadie les había hablado nunca de tal maravilla constructiva.

Pero volvamos a un cierto optimismo. En los últimos diez años, al menos los que la han cursado, sí la conocen, e incluso los más entusiastas la quieren saber construir con sus propias manos ${ }^{(17)}$.

\section{Notas}

(1) Ángel Truñó, Construcción de bóvedas tabicadas, edición a cargo de Santiago Huerta y José Luis González Moreno-Navarro; prólogo de Santiago Huerta; ensayo introductorio de José Luis González Moreno-Navarro. Madrid: Instituto Juan de Herrera, Escuela Técnica Superior de Arquitectura, 2004

(2) José Luis González, "La bóveda tabicada: pasado y futuro de un elemento de gran valor patrimonial", ensayo introductorio de Ángel Truñó, Construcción de bóvedas tabicadas, pág. XXXVIII

- Los proyectos hospitalarios de Doménech: entre el rigor arquitectónico y la proclama nacionalista, en $V$ Jornadas Gaudinistas. Gaudí y el Modernismo, Barcelona, 1999

(3) Ver Ramazzotti, L. "La cupola per St. John the Divine di Rafael Guastavino", en Lo specchio del cielo», Roma, 1997. Ver la traducción al castellano en AA.VV. Las Bóvedas de Guastavino en América: libro publicado con ocasión de la exposición «Guastavino Co. (1885-1962): la reinvención de la bóveda», edición a cargo de: Santiago Huerta. [Madrid], 2001, pp. 187200.

(4) La reconversión de la Casa Fuster en hotel ha estado promovida por Hoteles Center y ha sido proyectada y dirigida por GCA Arquitectes Associats.
(5) José Luis González, op. cit., pág. LI Y LII.

(6) La reconversión de la fábrica de Ca l'Aranyó ha sido proyectada por Antoni Vilanova y Eduard Simó, arquitectos.

(7) XXVII Cursillo sobre la Intervención en el Patrimonio Arquitectónico. 16-19 Diciembre 2004. De técnica restauratòria, el debate pendiente: las estructuras históricas... substitución o conservación. Un completo resumen de todas las ponencias se encuentra en el número de febrero de 2005 INDE (Informació i Debat) revista del Colegio de Arquitectos de Cataluña.

${ }^{(8)}$ José Luis González, op. cit., pág. XLVII y ss.

${ }^{(9)}$ La prueba de carga ha sido realizada por COTCA S. A.

(10) José Luis González, op. cit., pág. XLIV.

(11) Los casos ya citados se presentaron en:

Antoni Vilanova y Eduard Simó La rehabilitación del conjunto industrial de Ca l'Aranyó para la Universitat Pompeu Fabra (UPF).

Jordi Rogent, Josep Riu, La nueva reconversión en hotel de la Casa Fuster, última obra de Lluís Domènech i Montaner.

Las tres conferencias anteriores fueron:

Xavier Fabré Recuperación de la Cúpula de Guastavino 18812002.

Santiago Huerta Diagnosis: La modelización de la bóveda a la catalana.

Riccardo Gulli Restauración: la bóveda tabicada y la volta in foglio en Italia.

(12) Mar Loren, La obra de Rafael Guastavino en Nueva York Kent Diebolt, Investigaciones visuales, táctiles y no destructivas de las bóvedas y cúpulas de Guastavino en Estados Unidos Charles DiSanto, La restauración de las bóvedas del puente de Queensboro.

(13) S. Huerta, "La mecánica de las bóvedas tabicadas en su contexto histórico: las aportación de los Guastavino", en AA,.VV. op. cit.

(14) Casals, A., González, J.L., "Gaudí y el misterio de la encarnación. (Las incógnitas de la Cripta de la Colonia Güell)", en «Informes de la Construcción», $\mathrm{n}^{\circ}$ 408, 1990.

Casals, González, J.L., A., Roca, P., "La comprensión de la realidad del monumento: el caso de la Cripta de la Colonia Güell", en «Informes de la Construcción», nº 427, 1993a.

(15) José Luis González, op. cit., pág. XLIX.

- "Configuración constructiva y comportamiento mecánico de las bóvedas tabicadas en la construcción catalana del XIX", en Actas del III Congreso de Historia de la Construcción, Sevilla, 2000.

(16) Moya Blanco, L., Bóvedas tabicadas, Madrid, 1947.

(17) Por iniciativa del Instituto Gaudí de la Construcció y en sus instalaciones de Cornellá, alumnos de la Escuela de Arquitectura de Barcelona interesados en la conservación del patrimonio realizan prácticas reales de construcción de bóvedas tabicadas. 